\title{
Anomalous right coronary artery originating from the left main stem
}

\author{
Daniel Bromage, Toby Hall, Rob Lowe
}

Royal United Hospital, Bath, UK

Corresponding to Daniel Bromage, danbromage@doctors.org.uk

\section{DESCRIPTION}

An old man with no cardiac history presented with breathlessness at rest and worsening exercise tolerance. Physical examination revealed an ejection systolic murmur and signs of left ventricular failure. The admission ECG showed voltage criteria for left ventricular hypertrophy with anterolateral repolarisation abnormalities. An urgent echocardiogram confirmed severe stenosis of a trileaflet aortic valve. Coronary angiography prior to aortic valve replacement demonstrated an anomalous dominant right coronary artery (RCA) originating from the left main stem but no atherosclerotic changes (figure 1).
This finding is an extremely rare variant of the single coronary artery. The reported incidence of a single coronary system arising from the left sinus of Valsalva is $0.04 \%$, with an RCA originating from the left main stem accounting for $0.65 \%$ of these. ${ }^{1}$ A multidetector CT scan confirmed the diagnosis (figure 2) and demonstrated an RCA course between the aorta and the main pulmonary trunk.

This pathway can be associated with dynamic external compression by the great vessels causing angina pectoris, myocardial infarction, syncope and sudden death. ${ }^{2}$ However, in the absence of clinical or angiographic evidence of significant dynamic compression, the patient

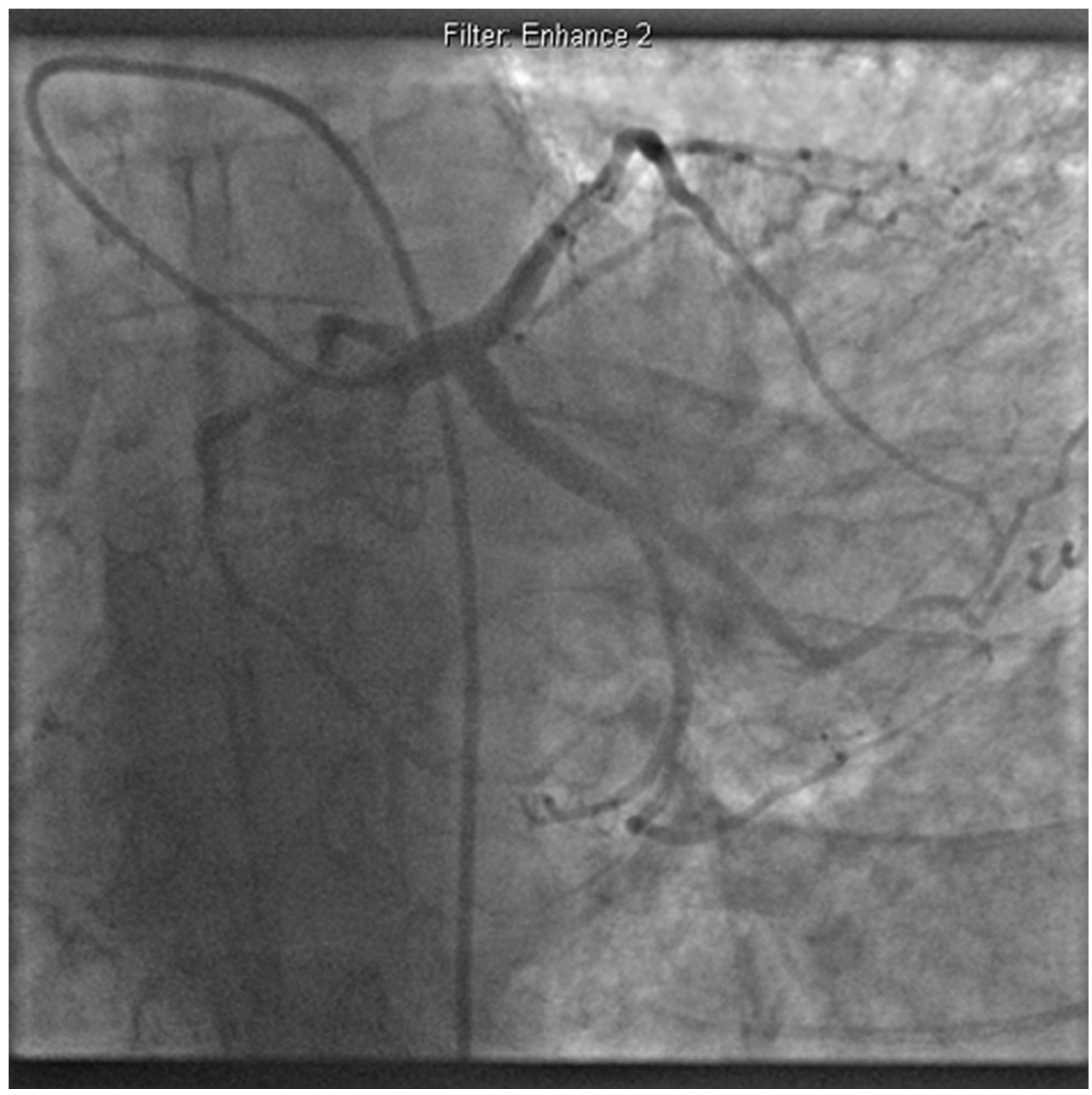

Figure 1 Coronary angiography demonstrating an anomalous right coronary artery originating from the left main stem. 


\section{BMJ Case Reports}

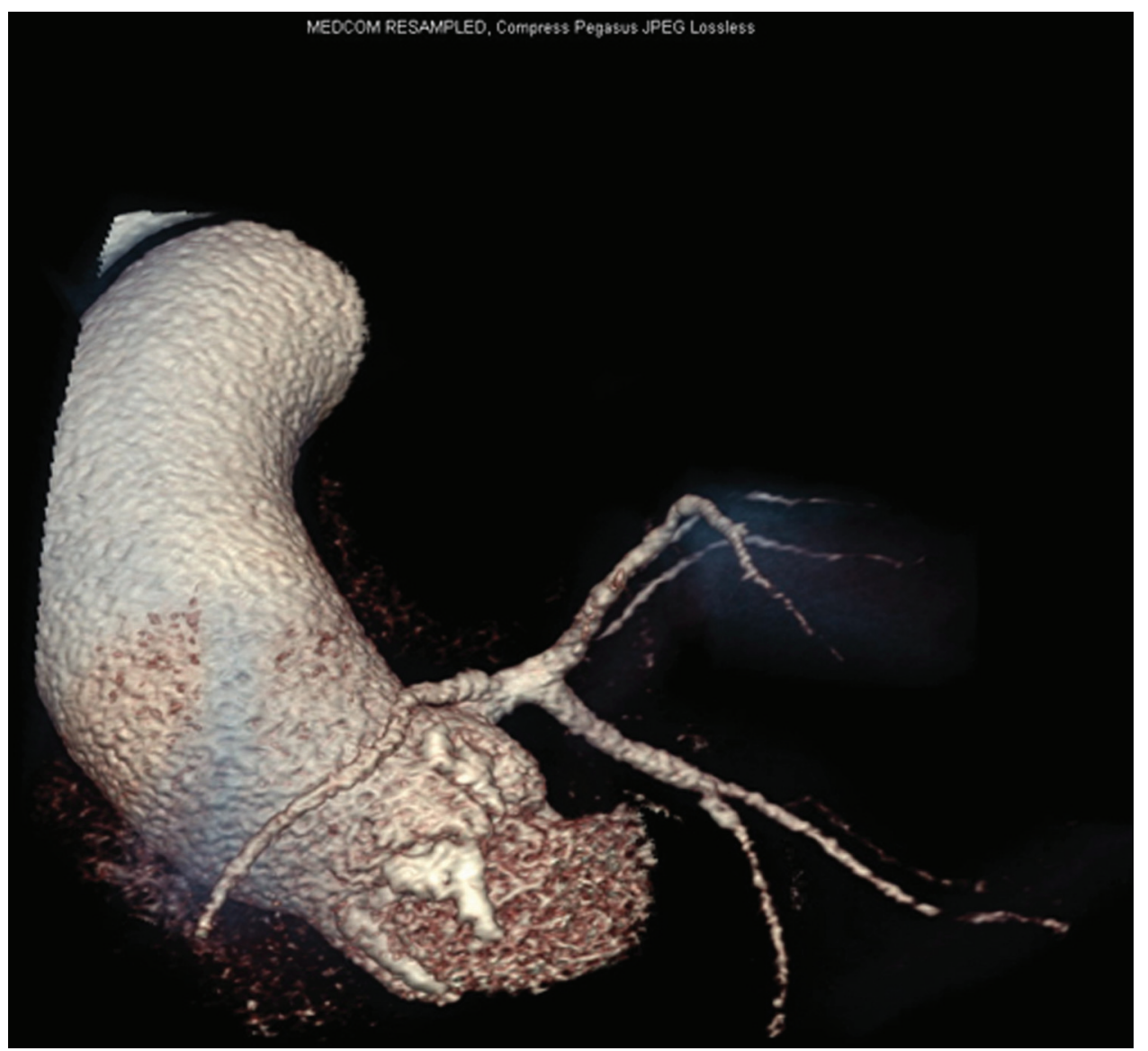

Figure 2 A multidetector CT scan demonstrating the anomalous right coronary artery originating from the left main stem.

subsequently underwent aortic valve replacement without re-implantation of the right coronary artery. He unfortunately died 2 weeks later as a consequence of left ventricular hypertrophy and myocardial fibrosis resulting from severe aortic stenosis.

This case illustrates a rare anomaly. Nonetheless, it should be remembered that it can have clinically significant consequences, and it is therefore important to evaluate any dynamic external compression.
Competing interests None.

Patient consent Not obtained.

\section{REFERENCES}

1. Yamanaka 0, Hobbs RE. Coronary artery anomalies in 126,595 patients undergoing coronary arteriography. Cathet Cardiovasc Diagn 1990;21:28-40.

2. Lopushinsky SR, Mullen JC, Bentley MJ. Anomalous right coronary artery originating from the left main coronary artery. Ann Thorac Surg 2001;71:357-8.

This pdf has been created automatically from the final edited text and images.

Copyright 2011 BMJ Publishing Group. All rights reserved. For permission to reuse any of this content visit http://group.bmj.com/group/rights-licensing/permissions.

BMJ Case Report Fellows may re-use this article for personal use and teaching without any further permission.

Please cite this article as follows (you will need to access the article online to obtain the date of publication).

Bromage D, Hall T, Lowe R. Anomalous right coronary artery originating from the left main stem. BMJ Case Reports 2011;10.1136/bcr.11.2010.3510, date of publication

Become a Fellow of BMJ Case Reports today and you can:

- Submit as many cases as you like

- Enjoy fast sympathetic peer review and rapid publication of accepted articles

- Access all the published articles

- Re-use any of the published material for personal use and teaching without further permission

For information on Institutional Fellowships contact consortiasales@bmjgroup.com

Visit casereports.bmj.com for more articles like this and to become a Fellow 